\title{
Comparison of roughness index for Kitka and Koznica wind farms
}

\author{
Bukurije Hoxha, Bedri Dragusha \\ University of Prishtina "Hasan Prishtina”, Faculty of Mechanical Engineering, Pristina, Kosovo
}

\begin{tabular}{|c|c|}
\hline Article Info & ABSTRACT \\
\hline Article history: & Kosovo has limited renewable energy resources and its power generation \\
\hline Received May 9, 2021 & $\begin{array}{l}\text { sector is based on fossil fuels. Such a situation emphasizes the importance of } \\
\text { active research and efficient use of renewable energy potential. According to }\end{array}$ \\
\hline Revised Jul 8, 2021 & the analysis of meteorological data for Kosovo, it can be concluded that \\
\hline Accepted Jul 23, 2021 & $\begin{array}{l}\text { among the most attractive potential wind power sites are the locations known } \\
\text { as Kitka }\left(42^{\circ} 29^{\prime} 41^{\prime \prime} \mathrm{N} \text { and } 21^{\circ} 36^{\prime} 45^{\prime \prime} \mathrm{E}\right) \text { and Koznica }\left(42^{\circ} 39^{\prime} 32^{\prime \prime} \mathrm{N}, 21^{\circ}\right.\end{array}$ \\
\hline Keywords: & $\begin{array}{l}\left.22^{\prime} 30^{\prime \prime} \mathrm{E}\right) \text {. The two terrains in which the analysis was carried out are } \\
\text { mountain areas, with altitudes of } 1142 \mathrm{~m} \text { (Kitka) and } 1230 \mathrm{~m} \text { (Koznica). the }\end{array}$ \\
\hline Energy yield & same measuring height, about $84 \mathrm{~m}$ above the ground, is obtained for these \\
\hline Mountain & average wind speeds: Kitka $6,667 \mathrm{~m} / \mathrm{s}$ and Koznica $6,16 \mathrm{~m} / \mathrm{s}$. Since the \\
\hline Roughness & $\begin{array}{l}\text { difference in wind speed is quite large versus a difference in altitude that is } \\
\text { not being very large, analyses are made regarding the terrain characteristics }\end{array}$ \\
\hline Wind direction & including the terrain relief features. In this paper it will be studied how much \\
\hline Wind speed & $\begin{array}{l}\text { the roughness of the terrain influences the output energy. Also, that the } \\
\text { assumption to be taken the same as to how much they will affect the annual } \\
\text { energy produced. }\end{array}$ \\
\hline
\end{tabular}

This is an open access article under the CC BY-SA license.

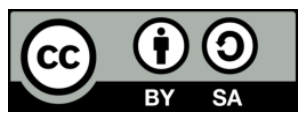

\section{Corresponding Author:}

Bedri Dragusha

Departement of Mechanical Engineering

University of Prishtina "Hasan Prishtina", Pristina, Kosovo

Email: bedri.m.dragusha@uni-pr.edu

\section{INTRODUCTION}

Because of the harmful consequences of pollution from the emissions of various gases, renewable energy sources increasingly gain in importance. The wind is a natural phenomenon related to the movement of air passes caused primarily by differential solar heating of the earth's surface [1], [2]. European countries by an agreement have decided to supply 20 percent of its total energy demand from renewable sources by 2020. We are now one year after that agreement, and we can see how far Kosovo has come in achieving this goal. This goal has been achieved by considering biomass as it is not widely used for heating needs, while other renewable sources remain largely in the shade. The potential is for all resources, but legal regulations have been able to develop to a limited extent. In two years (2008 and 2009), more than 24,000 MW of new power capacity based on wind energy was installed in the EU countries [1]. Nowadays, wind energy, as an alternative clean sustainable energy source, has been recognized as one of the fastest developing renewable energy source technologies. Wind power generation has made a remarkable contribution to daily life across the globe and has grown rapidly over the past 20 years [3]. As a renewable energy source with the highest growth rate in the last two decades, wind energy is considered a very important resource of electricity production in the future. The forecasts for the development of wind energy are highly optimistic and state that this type of energy will be important in the future [4], [5]. Wind turbines operate at altitude, and it is 
important to know what happens to air density as altitude increases. The density of air varies with altitude, so it is a decreasing function. So above, the air is lighter. This allows less aerodynamics to be created spontaneously [6], [7].

The primary meteorological factor in evaluating a prospective wind turbine site is the mean wind speed. Another important parameter is the anticipated extreme wind speed [8], [9]. Wind power plants generate electricity when the wind is blowing, and the plant output depends on the wind speed. Wind speeds cannot be predicted with high accuracy over daily periods, and the wind often fluctuates from minute to minute and hour to an hour [10], [11]. In fact, the wind also varies every second due to turbulence caused by land features, thermal sources, and specific weather conditions. It also blows more strongly higher above the ground than closer to it, due to surface friction [12], [13].

Total energy production and capacity factor are fundamental aspects of a wind power project. To determine the optimum energy output, it is essential to select the right turbine design for a location [14]. Wind turbine operation is dependent on wind speeds to generate power [15]. Sustainability evaluation of wind resources can be performed using different approaches that are complementary between each other: thermo-economic analysis (energy and/or exergy calculations), life cycle assessment (which is a multicriteria product-oriented analysis), emergy approach (a holistic approach donor side oriented). These different assessment approaches were compared one by one and/or combined [16], [17].

Annual energy produced is typically calculated referring to the annual mean wind speed of the site. Unfortunately, the annual average wind speed varies significantly [18]. Operation of the individual wind turbines may be adversely impacted by the turbulent wakes from other upwind turbines, with the magnitude of the impact depending largely on the turbines' respective rotor sizes and distance between one another, as well as on the overall shape of the wind farm and turbine spacing therein [19]. Wind shear in open ground when dealing with distances e.g., $10 \mathrm{~m}$ in it have a greater effect than what is found in the field. Now increasing the height these do not have high impact. This effect, however, has the effect of reducing the energy generated by a turbine, and then the entire wind farm [20], [21]. The electricity factor produced by wind energy ranges from 20 to 40\%, in general [22], [23]. The value of the capacity factor for wind turbines in Kosovo is estimated to be $25 \%$ [24]. Based on the analysis done, we can assess precisely whether these two places have the potential to contribute to the local energy production.

\section{RESEARCH METHOD}

The methodology used in this paper consists of consulting, studying, analyzing, and comparing the data for wind speed, wind direction and the main components to analyze the roughness in those terrains. In this case there are used one year measurement for two wind farms, Kitka and Koznica. This method of analysis is simple, and we assume or hypothesize that: in our case we are dealing with two mountain terrains, we have the same wind direction, and their geographical coordinates (Koznica: N 42.59880 ${ }^{\circ}$; E 21.35468 , Kitka $\mathrm{N} 42.3956^{\circ} \mathrm{E} 21.3936^{\circ}$ ) are very close so we will expect to have results same to the effect of roughness.

\subsection{Site description and data's for Koznica}

The WPP Koznica is in Kosovo, approximately $16 \mathrm{~km}$ south-east of Pristina and $7 \mathrm{~km}$ west of Novo Brdo. For the analysis of wind characteristics and wind energy potential of the Koznica site, the measurement data for the one-year period 01/05/2015 - 30/04/2016 have been used. The turbines presented in Table 1, are not located at the same distances, due to the unsuitable terrain, but the placement was done using WAsP software.

Table 1. Details of all turbines placed in Koznica

\begin{tabular}{cccc}
\hline Turbine no. & \multicolumn{2}{c}{ Coordinate of turbine placement } & $\begin{array}{c}\text { Level above sea } \\
\text { X }(\mathrm{m})\end{array}$ \\
\hline "T1" & 529087 & $\mathrm{Y}(\mathrm{m})$ & 1009 \\
"T2" & 528927 & 4716298 & 1009 \\
"T3" & 528909 & 4716930 & 1027 \\
"T4" & 529631 & 4717540 & 996 \\
"T5" & 529051 & 4717188 & 988 \\
"T6" & 528709 & 4718563 & 998 \\
"T7" & 528910 & 4718886 & 1084 \\
"T8" & 529198 & 4720283 & 1052 \\
"T9" & 529555 & 4719972 & 1081 \\
"T10" & 529843 & 4719986 & 1071 \\
\hline
\end{tabular}

Koznica is determined with the database ESA Globcover 2009. Modeling of the terrain roughness was conducted by estimating the roughness length of the field in accordance with the methodology of the 
European Atlas of the winds. By using this database and the software package WAsP Map Editor, the map of the roughness of terrain was made that included a wider target region comprising $20 \times 20 \mathrm{~km}^{2}$ of the territory of the target region. Changes in the roughness of the terrain of the target region Koznica, which was used for making the WAsP folder, is shown in the satellite image of the terrain (Google Earth) in the figure below. In this figure, the location of WPP Koznica is indicated with red contour line. The terrain shown in Figure 1 on which the construction of WPP Koznica is planned is relatively simple in terms of roughness and can be described with afforested valleys with relatively high roughness, and bared ridges where the construction of wind turbines is planned. Layout of ten wind turbines in Koznica is well shown in Figure 2, where the sitting of them is focused in that way that tends to save $3 \mathrm{D}$ distance.

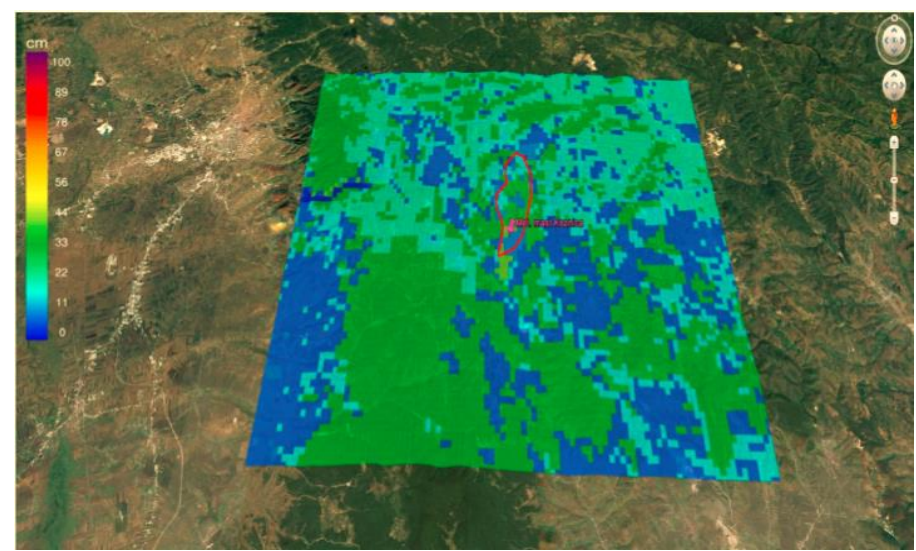

Figure 1. The roughness map of the wider terrain at the target region of WPP Koznica (which is indicated in red contour line)

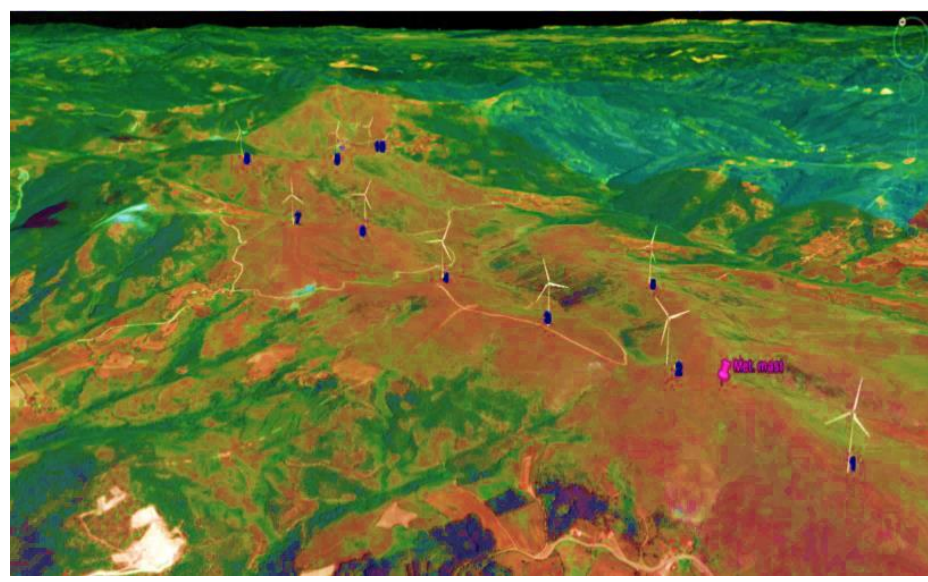

Figure 2. Layout for the 10 turbines for the project WPP Koznica

\subsection{Site description and data for Kitka}

Kitka wind farm site is in a complex mountainous region, shown in Figure 3. Although the slopes of the terrain were high, no cliffs were observed. Turbines are planned on the plateau of mountain ridge running northwest-southeast direction. Site elevations range from $960 \mathrm{~m}$ to $1090 \mathrm{~m}$ from sea level. The terrain here is made up of grass of agricultural land and forest areas [25], [26]. Since we are dealing with mountainous terrain, then here too there are trees, but they are far from the place where the wind turbines are placed. Lowdensity rural settlements are present in the vicinity, and this has been taken into consideration while wind turbine micro siting. 


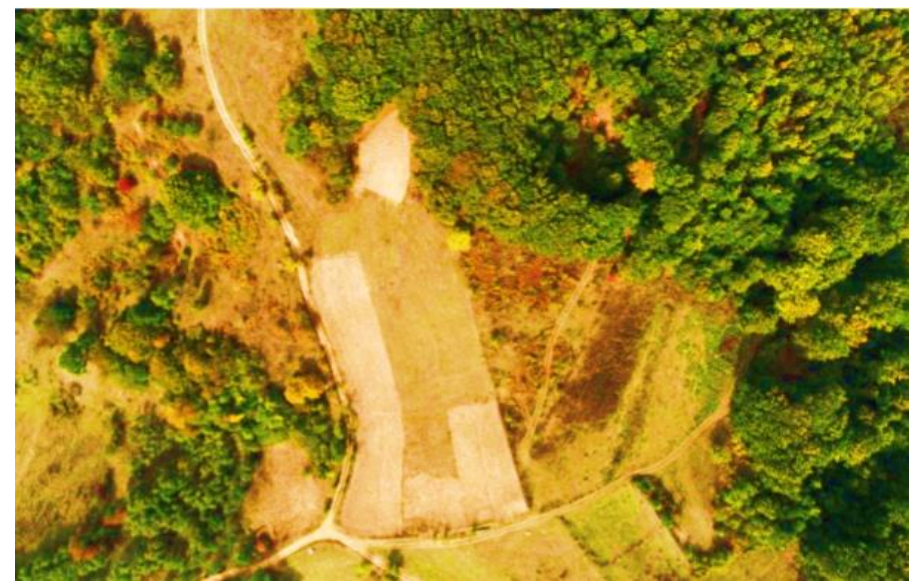

Figure 3. View of Kitka terrain where turbines are mounted (photo taken before mounting)

Site consists of 7 units of GE3.6 MW turbines and 3 units of GE3.2 MW turbines, as shown in Figure 4. Turbines are located regarding wind potential, site accessibility, public land usage and private land usage. Same as in Koznica case, there also is tended to save the distance of 3D distance between them. In the case of Kitka since we have a change in the capacity of the turbines, looking at Figure 4 it may seem that 3D distance is not saved here. But even here this distance is maintained, but since the capacity changes then their diameter also changes as is presented in Table 2, when we have 3.6 MW and 3.2MW. The wind farm consists of 7 units of GE 3.6 MW turbines and 3 units of GE 3.2 MW turbines where the positions of them is presented in Table 3. The turbines are located regarding wind potential, site accessibility, public land usage and private land usage.

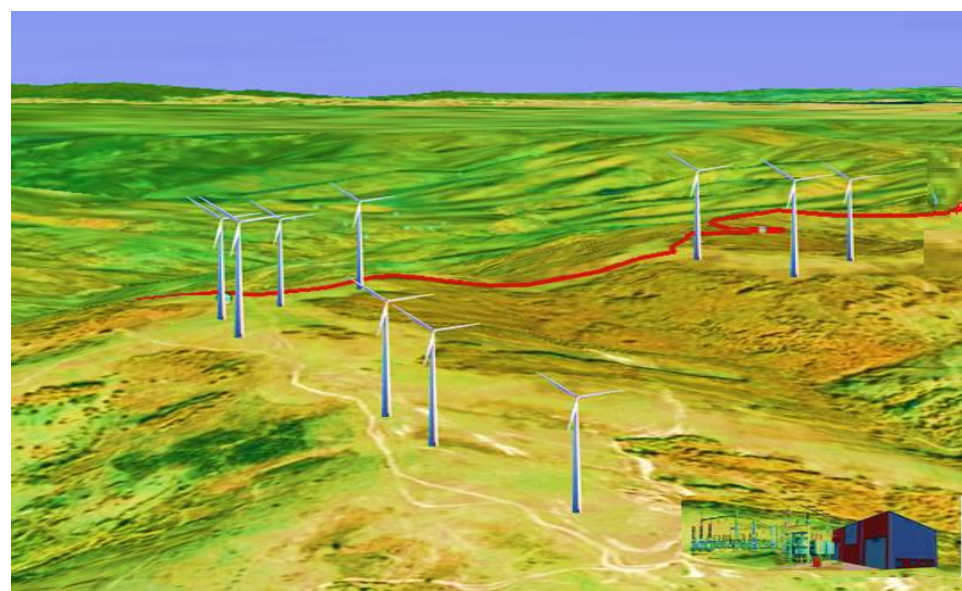

Figure 4. 10 wind turbines in Kitka wind park

Table 2. Turbine layout summary, used in Kitka wind farm

\begin{tabular}{ll}
\hline Turbine type & $7 \times$ GE 3.6-137 \\
& $3 \times$ GE 3.2-130 \\
\hline Hub height & $110 \mathrm{~m}$ \\
Rated power & $3600 \mathrm{~kW} \& 3200 \mathrm{~kW}$ \\
Number of turbines & 10 \\
Installed capacity & $34.8 \mathrm{MW}$ \\
\hline
\end{tabular}

Table 3. Placement of wind turbines and coordinates for wind farm in Kitka

\begin{tabular}{cccc}
\hline Turbine No. & X & Y & Level above sea $(\mathrm{m})$ \\
\hline T1 & 544918 & 4726483 & 966.6 \\
T2 & 545205 & 4725695 & 1000.0 \\
T3 & 546034 & 1726525 & 1039.0 \\
T4 & 546423 & 4726094 & 1019.9 \\
T5 & 546741 & 4725671 & 1090.0 \\
T6 & 547076 & 4725999 & 1060.0 \\
T7 & 547427 & 4726226 & 1031.8 \\
T8 & 546545 & 4724341 & 1070.0 \\
T9 & 546878 & 4723993 & 1080.0 \\
T10 & 547258 & 4724234 & 1040.0
\end{tabular}




\subsection{Basis for comparison between the two locations}

From the data presented and those measured in the field, some comparisons can be made for the two wind parks, as:

- Comparison of the change in wind speed over the months

- Comparison of altitude for each turbine in the two wind parks

- Comparison of the level of the terrain roughness index

- Comparison of horizontal distance between the wind turbines in the respective parks

Duration of minimum wind speed needed to start wind turbine and maximum wind speed is also presented for two locations.

\section{RESULTS AND DISCUSSION}

The diagrams in the following figures present comparison of several important parameters between the two locations. The diagram in Figure 5 presents mean wind speed for two locations measured in same height, $84 \mathrm{~m}$. As we can see, in Figure 5, as mean wind speed is higher in Kitka, also for different months in Kitka, wind speed is higher. In the same figure we presented the wind direction for Kitka and Koznica for one year measurement in those locations. In the other part, In Figures 6 (a)-(b) we presented the wind direction for Kitka and Koznica for one year measurement in those locations, where a is for Kitka and $b$ for Koznica. The predominant direction can be seen to be mainly from the south-east, for both wind farms.

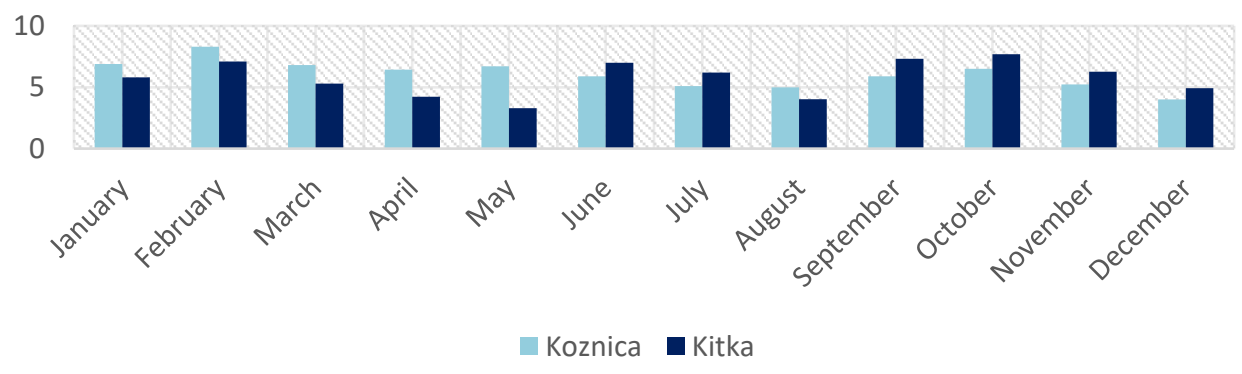

Figure 5. Comparison of Kitka and Koznica mountains monthly wind speed

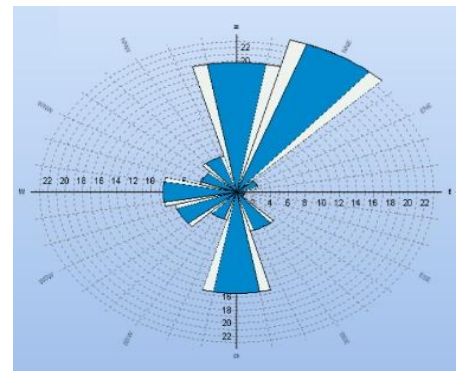

(a)

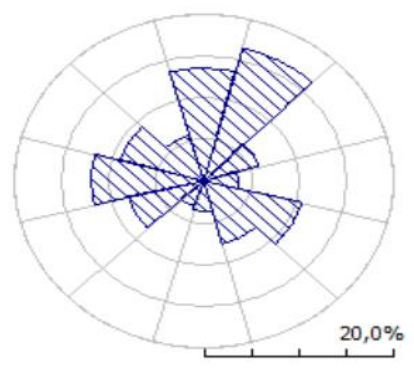

(b)

Figure 6. Comparison of Kitka and Koznica mountains wind direction, (a) Kitka and (b) Koznica

Wind direction is an element that must be taken into consideration in comparison to a large extent and especially for real installation. To accurately assess the direction of the wind in a place we need measurements of at least one year. Elevation is also of high importance, as can be seen in Figure 6, altitude is higher in Koznica, and in turbines T8 and T9. 


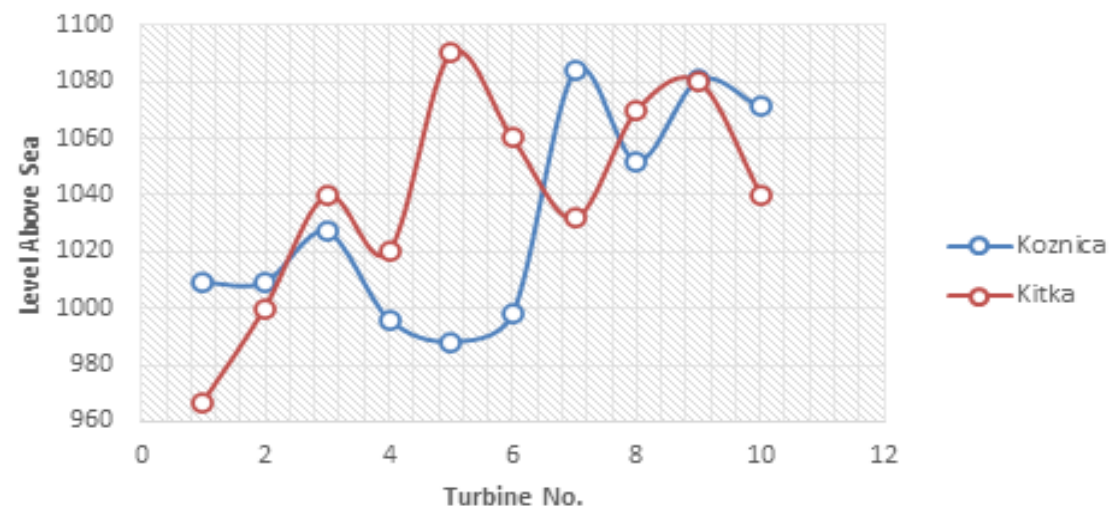

Figure 7. Comparison between the altitude at which the wind turbines are installed

The ruggedness index (RIX) is described in detail in Bowen (1996), Mortensen (1997), and Bowen (2004). The following conclusions regarding RIX can be made:

- If the RIX is close to zero, then the terrain is generally less steep then 0.3 and the airflow in the region is likely to be attached.

- If the RIX is greater than zero, then parts of the terrain are steeper than 0.3 and flow separation may occur in some sectors [27], [28].

dRIX is the orographic performance indicator.

$$
d R I X=R I X_{W T G} R I X m e t, \text { mast }
$$

Those indicator relationships are described in Figure 7 for Kitka and Koznica, and as we show in diagram. For Kitka as dRIX values between met mast and turbine locations are in the range of $2-8 \%$, similarity principle can be said to be mostly achieved. For Koznica it can be concluded that the prediction of production for wind turbines $1-8$ is generally acceptable, while for the turbine 9 and 10 the uncertainty in the estimation of production is significantly higher because dRIX for turbine 9 is $8 \%$, and for turbine 10 it is $11 \%$. In addition, the turbines 8, 9 and 10 are located at about $4 \mathrm{~km}$ of the measuring mast, so the estimation of potential in these locations is with significant uncertainty.

From what we can see from the installation of wind turbines for both parks, referred to as Kitka and Koznica, it follows that the turbines T1 and T2 have the larger distance compared with other turbines in Kitka and same turbines T7 and in Koznica, and when we compare energy production those distances are very interested in wind turbines interaction and total energy production.

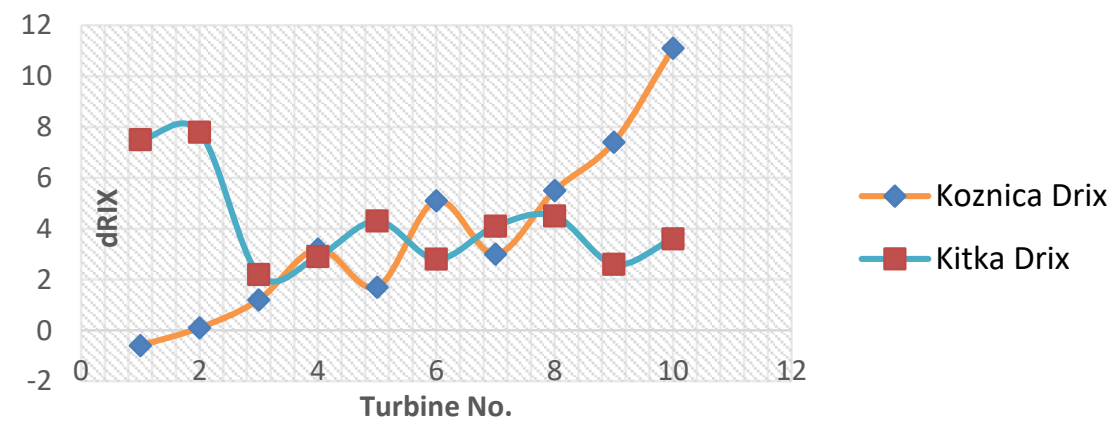

Figure 8. Relationship between RIX and dRIX, for Koznica and Kitka wind parks

\section{CONCLUSIONS}

The part that is currently operating as a wind park, Kitka is located on the eastern side of Kosovo and also the site where measurements were made in that part, namely Koznica. The analysis shows that Kitka has a dRIX bigger than Koznica, but even this harshness of terrain has not affected the overall potential 
energy production as much as the wind speed, due to the shape of the terrain that enables it. Many times, in the case of practical realization when we are dealing with the same terrains, as in this mountainous case and when approximately the wind blows in one direction, RIX are taken the same. From this analysis we can conclude that this approach should not be such. Regarding the efficiency of the turbines used, it depends largely on the wind speed, but the height of the turbines is an important factor as well, due to the velocity change with height. Calculations show that turbines have the highest efficiency, as expected, at Kitka, due to the higher wind speeds. On the other hand, as mentioned above, there were two different types of capacity turbines, 3.2 MW and 3.6 MW. An element that has an impact on the overall power generation is the distance between the turbines. For stable operating conditions, it is necessary for them to stay in $3 \cdot \mathrm{D}$ distances. If we consider that the turbines will be in operation for 5000 hours during the year, then this will result in annual production of about: 55829.4 MWh at Koznica, and 55019.873 MWh at Kitka wind park, and totally 110.849 $\mathrm{GWh}$. The difference of energy production from those two wind farms is $809.527 \mathrm{MWh}$. According to data from the Energy Regulatory Office of Kosovo, it follows that the annual average of energy used in Kosovo is $5835000 \mathrm{GWh} /$ year, so by using those wind farms, we will have $0.0018 \%$ of electrical energy generated by those two wind farms.

\section{REFERENCES}

[1] D. Lombardi, "Dynamics of offshore wind turbines," MSc thesis, University of Bristol: Bristol, UK, 2010.

[2] A. H. Almukhtar, "Effect of drag on the performance for an efficient wind turbine blade design," Energy Procedia, vol. 18, pp. 404-415, 2012, doi: 10.1016/j.egypro.2012.05.052.

[3] W. Prosmen, S. Janjai, and T. Tantalechon, "An Analysis of wind energy potential of Kampot Province, Southern Cambodia,” Energy Procedia, vol. 52, pp. 633-641, 2014, doi: 10.1016/j.egypro.2014.07.119.

[4] V. Mijakovski, "Review of wind energy potential and experiences from operation of the first wind park in Republic of Macedonia," Conference: 18th Symposium on Thermal Science and Engineering of Serbia at: Sokobanja, Serbia, 2017.

[5] S. Osmanaj, B. Hoxha, and R. Selimaj, “An experimental study of wind data of a wind farm in Kosovo," Przeglad Elektrotechniczny, vol. 94, no. 7 pp. 21-25, 2018, doi: doi:10.15199/48.2018.07.05.

[6] B. Hoxha, R. Selimaj, and S. Osmanaj, "An experimental study of Weibull and Rayleigh distribution functions of wind speeds in Kosovo," Telecommunication, Computing, Electronics and Control TELKOMNIKA, vol. 16, no. 5, pp. 2451-2457, 2018, doi: 10.12928/TELKOMNIKA.v16i5.10260.

[7] J. P. Mellado, "Using numerical simulations to study the atmospheric boundary layer," Direct and Large Eddy Simulation XII, DLES 2019, ERCOFTAC Series, vol. 27, Springer Cham, 2020.

[8] J. F. Manwell, J. G. McGowan, and A. L. Rogers, Wind energy explained: theory, design, and application, John Wiley \& Sons, 2010.

[9] K. W. Corscadden, A. Thomson, B. Yoonesi, and J. McNutt, "The impact of variable wind shear coefficients on risk reduction of wind energy projects," International scholarly research notices, vol. 2016, ID. 5790464, pp. 1-12, 2016, doi: 10.1155/2016/5790464.

[10] H. Ibrahim, M. Ghandour, M. Dimitrova, A. Illinca, and J. Perron, "Integration of wind energy into electricity systems: technical challenges and actual solutions," Energy Procedia, vol. 6, pp. 815-824, 2011, doi: 10.1016/j.egypro.2011.05.092.

[11] O. N. Laban, C. M. Maghanga, and K. Joash, "Determination of the surface roughness parameter and wind shear exponent of Kisii Region from the on-site measurement of wind profiles," Journal Energy, vol. 2019, ID. 8264061, pp. 1-12, 2019, doi: 10.1155/2019/8264061.

[12] H. P. Dhariwal, and B. K. Roy, "Effect of lift on wind turbine blade design parameter," International Journal of Engineering Research \& Technology, vol. 3, no. 1, pp. 290-292, 2014.

[13] A. Haghshenas, and J. P. Mellado, "Characterization of wind-shear effects on entrainment in a convective boundary layer," Journal of Fluid Mechanics, vol. 858, pp. 145-183, 2019.

[14] M. Gul, N. Tai, W. Huang, M. H. Nadeem, and M. Yu, "Assessment of wind power potential and economic analysis at Hyderabad in Pakistan: Powering to local communities using wind power," Sustainability, vol. 11, no. 5, pp. 1-23, 2019, doi: doi:10.3390/su11051391.

[15] A. L. Diaconita, L. Rusu, and G. Andrei, "A local perspective on wind energy potential in six reference sites on the western coast of the black sea considering five different types of wind turbines," Inventions, vol. 6, no. 3, pp. 1-14, 2021, doi: 10.3390/inventions6030044.

[16] S. Paudel, M. Santarelli, V. Martin, B. Lacarriere, and O. L. Corre, "Wind resource assessment in europe using emergy," Journal of Environmental Accounting and Management, vil. 2, no. 4, pp. 347-366, 2015, doi: 10.5890/JEAM.2014.12.006.

[17] A. Ezzaidi, M. Elyaqouti, L. Bouhouch, and A. Ihlal, "Evaluation of the energy performance of the amougdoul wind farm, Morocco," International Journal of Electrical and Computer Engineering IJECE, vol. 7, no. 2, pp. 692705, 2017, doi: 10.11591/ijece.v7i2.pp692-705.

[18] W. Langeder, Wind resource and site assessment, Wind \& Site, Suzlon Energy, Århus, Denmark, 2010. 
[19] E. D. Kimberly, and E. J. Crivella, "Wind turbine wakes, wake effect impacts, and wind leases: using solar access laws as the model for capitalizing on wind rights during the evolution of wind policy standards," Duke Environmental Law \& Policy Forum, vol. 22, no. 1, 2011.

[20] M. L. Ray, A. L. Rogers, and J. G. McGowan, "Analysis of wind shear models and trends in different terrains," University of Massachusetts, Department of Mechanical \& Industrial Engineering Renewable Energy Research Laboratory, pp. 1-14, 2017.

[21] D. Mohammed, A. S. M. Abdelaziz, E. Mohammed, and E. Elmostapha, "Wind speed data and wind energy potential using weibull distribution in Zagora, Morocco," International Journal of Renewable Energy Development, vol. 8, no. 3, pp. 267-273, 2019.

[22] M. Ayala, J. Maldonado, E. Paccha, and C. Riba, "Wind power resource assessment in complex terrain: villonaco case-study using computational fluid dynamics analysis," Energy Procedia, vol. 107, pp. 41-48, 2017, doi: 10.1016/j.egypro.2016.12.127.

[23] K. Azizi, M. Farsadi, and M. F. Kangarlu, "Efficient approach to LVRT capability of DFIG-based wind turbines under symmetrical and asymmetrical voltage dips using dynamic voltage restorer," International Journal of Power Electronics and Drive System (IJPEDS), vol. 8, no. 2, pp. 945-956, 2017, doi: 10.11591/ijpeds.v8.i2.pp945-956.

[24] W. Tong, "Fundamentals of wind energy," Kollmorgen Corporation, Virginia, USA, WIT Transactions on State of the Art in Science and Engineering, 2010.

[25] B. Dragusha, and B. Hoxha, "Impact of field roughness and power losses, turbulence intensity on electricity production for an onshore wind farm," International Journal of Power and Drive System (IJPEDS), vol. 11, no. 3, pp. 1519-1526, 2020, doi: 10.11591/ijpeds.v11.i3.pp1519-1526.

[26] M. Blackwood, "Maximum Efficiency of a Wind Turbine," Undergraduate Journal of Mathematical Modeling: One + Two, University of South Florida, vol. 6, no. 2, pp. 1-12, 2016.

[27] Michael Green, "Using mesoscale meteorological models to assess wind energy potential," MSc thesis, Environmental Science, University of Canterbury, 2005.

[28] N. Cherkaoi, A. Belqih, F. E. Mariami, J. Boukherouaa, and A. Berdai, "Optimal location and reactive power injection of wind farms and SVC's units using voltage indices and PSO," International Journal of Electrical and Computer Engineering IJECE, vol. 9, no. 5, pp. 3407-3414, 2019, doi: 10.11591/ijece.v9i5.pp3407-3414. 